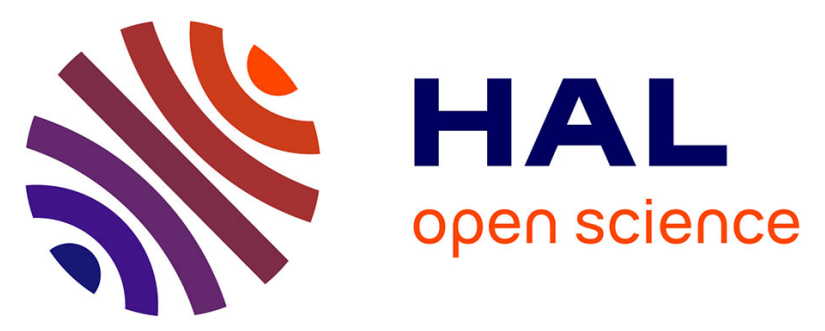

\title{
Measuring Leaf Penetration and Volatilization of Chlorothalonil and Epoxiconazole Applied on Wheat Leaves in a Laboratory-Scale Experiment
}

Nebila Lichiheb, Carole Bedos, Erwan Personne, Pierre Benoit, Valerie Bergheaud, Olivier Fanucci, Jihene Bouhlel, Enrique Barriuso

\section{To cite this version:}

Nebila Lichiheb, Carole Bedos, Erwan Personne, Pierre Benoit, Valerie Bergheaud, et al.. Measuring Leaf Penetration and Volatilization of Chlorothalonil and Epoxiconazole Applied on Wheat Leaves in a Laboratory-Scale Experiment. Journal of Environmental Quality, 2015, 44 (6), pp.1782-1790. 10.2134/jeq2015.03.0165 . hal-01256484

\section{HAL Id: hal-01256484 https://hal.science/hal-01256484}

Submitted on 14 Jan 2016

HAL is a multi-disciplinary open access archive for the deposit and dissemination of scientific research documents, whether they are published or not. The documents may come from teaching and research institutions in France or abroad, or from public or private research centers.
L'archive ouverte pluridisciplinaire HAL, est destinée au dépôt et à la diffusion de documents scientifiques de niveau recherche, publiés ou non, émanant des établissements d'enseignement et de recherche français ou étrangers, des laboratoires publics ou privés. 


\title{
Measuring Leaf Penetration and Volatilization of Chlorothalonil and Epoxiconazole Applied on Wheat Leaves in a Laboratory-Scale Experiment
}

\author{
Nebila Lichiheb, Carole Bedos, ${ }^{*}$ Erwan Personne, ${ }^{*}$ Pierre Benoit, Valérie Bergheaud, \\ Olivier Fanucci, Jihene Bouhlel, and Enrique Barriuso
}

\begin{abstract}
Estimation ofpesticide volatilization from plants is difficult because of our poor understanding of foliar penetration by pesticides, which governs the amount of pesticide available for volatilization from the leaf surface. The description of foliar penetration is still incomplete because experimental measurements of this complex process are difficult. In this study, the dynamics of leaf penetration of ${ }^{14} \mathrm{C}$-chlorothalonil and ${ }^{14} \mathrm{C}$-epoxiconazole applied to wheat leaves were measured in a volatilization chamber, which allowed us to simultaneously measure pesticide volatilization. Fungicide penetration into leaves was characterized using a welldefined sequential extraction procedure distinguishing pesticide fractions residing at different foliar compartments; this enabled us to accurately measure the penetration rate constant into the leaves. The effect of pesticide formulation was also examined by comparing formulated and pure epoxiconazole. We observed a strong effect of formulation on leaf penetration in the case of a systemic product. Furthermore, the penetration rate constant of formulated epoxiconazole was almost three times that of pure epoxiconazole ( $0.47 \pm 0.20$ and $0.17 \pm 0.07$, respectively). Our experimental results showed high recovery rates of the radioactivity applied within the range of 90.5 to $105.2 \%$. Moreover, our results confirm that pesticide physicochemical properties are key factors in understanding leaf penetration of pesticide and its volatilization. This study provides important and useful parameters for mechanistic models describing volatilization of fungicides applied to plants, which are scarce in the literature.
\end{abstract}

\section{Core Ideas}

- Volatilization and leaf penetration of two wheat fungicides were simultaneously measured.

- A laboratory system and ${ }^{14} \mathrm{C}$-labeled compounds were used.

- Residues on and in leaf were quantified with a well-defined chemical extraction procedure.

- High effect of the formulation was shown for systemic product. - Penetration rate constant, which are scarce in the literature, were provided.

Copyright $\odot 2015$ American Society of Agronomy, Crop Science Society of America, and Soil Science Society of America. 5585 Guilford Rd., Madison, WI 53711 USA.

All rights reserved.

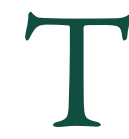
HERE ARE GROWING CONCERNS over the occurrence of pesticides in the atmosphere due to their immediate impact on human health (Viel and Richardson, 1993) and on ecosystems (Führ et al., 1998; Bakker et al., 1999). Volatilization of pesticides after application to soil or plants may represent a major emission pathway for losses to the atmosphere, accounting for up to several percentage of the application dose in some cases (Bedos et al., 2002). The main factors affecting volatilization of pesticides after application are their physicochemical properties, environmental conditions, and agricultural practices (Stork et al., 1994; van den Berg et al., 1999). It has been demonstrated experimentally that the volatilization rates from plant surfaces are higher than from soil surfaces due to the lower adsorption capacity of plants (Boehncke et al., 1990) and to the larger surface of exchange than soil (Rüdel, 1997). However, the prediction of this transfer pathway remains problematic, mainly because of our poor understanding of processes competing with volatilization at the leaf surface, such as penetration into plant leaves, degradation due to chemical and photo-chemical reactions, and wash-off by rainfall (Leistra, 2005; Leistra and van den Berg, 2007; Lichiheb et al., 2014). This study focuses on the evaluation of the leaf penetration process to better estimate the fraction of pesticide residues on leaves available for volatilization. The photodegradation is not discussed here. Although the rainfall wash-off potential was measured, this process is not the main focus of this study because it would then be necessary to study additional processes as rainfall interception by leaves, which was not the purpose of this study. The foliar penetration of pesticide is the decisive process influencing the effectiveness of pesticides and thus their fate in the environment (de Ruiter et al., 2004). It is the most immediate process occurring just after pesticide application (Breeze et al., 1992). The factors influencing this process are (i) the plant properties, especially the permeability of the leaf cuticle (Chamel, 1986; Schönherr and Baur, 1994) (it was demonstrated that the cuticle is the main barrier for the leaf penetration of pesticides [Kirkwood, 1999; Wang and Liu, 2007]); (ii) the physicochemical properties of the pesticides, especially the lipophilicity (which can be characterized by the octanol/water
INRA AgroParisTech UMR1402 ECOSYS, F-78850 Thiverval-Grignon, France. Assigned to Associate Editor Paul Williams.

Abbreviations: PUF, polyurethane foam. 
partition coefficient) (Baker et al., 1992; Kerler and Schönherr, 1988); and (iii) the meteorological conditions (temperature and relative humidity) (Satchivi et al., 2001; Willis and McDowell, 1987).

Despite its complexity, the pesticide volatilization from plants can be experimentally determined at different scales, ranging from the field scale, via semifield experiments, to laboratory studies (Bedos et al., 2010; Kromer et al., 2004; Kubiak, 2002; Stork et al., 1994; van den Berg et al., 1995; Wolters, 2003). Furthermore, measured volatilization rates at semifield and field scale can be used to test models describing the volatilization process. Measured volatilization rates of fenpropimorph from bean and radish in a wind tunnel have been used to test the PEARL model (Leistra and Wolters, 2004), and measured volatilization rates of chlorothalonil and fenpropidin applied on wheat at the field scale have been used to test the SURFATM-Pesticides model (Lichiheb et al., 2014). In existing models for simulating pesticide volatilization from plants, leaf is often considered as a black box, and pesticide leaf penetration is described following a first-order kinetic reaction using estimated rate constants (Leistra and van den Berg, 2007; Trapp and Matthies, 1995; Trapp et al., 1994; Lichiheb et al., 2014). These rate constants are mainly adjusted to fit experimental findings or estimated indirectly on the basis of experimental results found in the literature. Due to the scarcity of data on the penetration rate constant of pesticide, Leistra (2005) proposed a classification of penetration rate on the basis of a diversity of experimental data. However, this classification has a considerable uncertainty because it is not specific to each pesticide. Direct measurements on the penetration rate of pesticides into plants are usually not available, mainly because experimental measurements of this process are still complex. In most cases the pesticide extraction is simplified, such as shaking leaves with solvent to estimate pesticide residues (Bedos et al., 2010; Leistra et al., 2006; van den Berg et al., 1995), and only considering the penetration of pesticides in plant cuticle and isolating it enzymatically (Kirsch et al., 1997; Santier and Chamel, 1998). A more detailed extraction procedure allowed the quantification of the pesticide fraction on the leaf surface and the penetrated fraction without distinguishing the penetrated fraction into the leaf cuticle and the penetrated fraction into the plant tissue (McCall, 1989).

To accurately measure the penetration rate constant of pesticide into the leaves, a refined measurement method distinguishing the pesticide fractions residing in the different compartments of the plant leaf (leaf surface deposited, adsorbed, and penetrated into the leaf cuticle or into the plant tissue) is needed. Furthermore, the effect of formulation should be considered in these measurements because both volatilization and leaf penetration are affected by pesticide formulation (Gauvrit and Dufour, 1990; Leistra, 2005). Adjuvants, defined as a substance without significant pesticide properties but added to aid or modify the activity of a pesticide, can fulfill different functions to enhance the effectiveness of a pesticide. Moreover, it is well known that several adjuvants may promote substantially the penetration of pesticides into the leaves, reducing the availability of the active ingredient for volatilization from the leaf surface (de Ruiter et al., 2003). Consequently, as found by McCall (1989), the leaf penetration coefficient can vary to a greater degree depending on the commercial formulation.
The first goal of this study was to establish an experimental set-up that allows direct simultaneous measurements of volatilization and penetration of pesticides applied on the leaf surface in controlled conditions. To achieve this goal, we used a small volatilization chamber that permits the use of ${ }^{14} \mathrm{C}$-labeled pesticides, allowing the overall mass balances. Using this setup, the dynamics of volatilization and leaf penetration of two current wheat fungicides, chlorothalonil and epoxiconazole, applied on leaves were measured. These chosen fungicides represent different mode of actions. Chlorothalonil is a contact pesticide (Caux et al., 1996), whereas epoxiconazole has a systemic action (Pareja et al., 2012). To obtain a realistic experimental rate constant of leaf penetration, a working assumption has been proposed to describe the fungicide distribution in leaves. In fact, the dynamics of the pesticide penetration were characterized by the localization of pesticide in three compartments of the plant leaf (leaf surface, leaf cuticle, and leaf tissue), which was estimated by successive extractions using adapted solvents. Furthermore, we investigated the effect of formulation by testing epoxiconazole as a pure substance and as a formulated product.

\section{Materials and Methods}

\section{Laboratory System}

A laboratory system (Fig. 1) was composed of three cylindrical volatilization chambers of approximately $5 \mathrm{~L}$ functioning in parallel during the experiments, representing three replicates per experiment. Each volatilization chamber was made of a glass jar with a steel perforated support installed about $7 \mathrm{~cm}$ above the chamber bottom. Three treated leaves with fungicide were placed above this support, which comprises two handles at both ends that are easily removable for sampling purposes. The outlet of each chamber was connected to a trapping system where volatilized pesticide is adsorbed. The trapping system consisted in four precleaned polyurethane foam (PUF) plugs (diameter, $22 \mathrm{~mm}$; length, $76 \mathrm{~mm}$ ) (Sigma-Aldrich) introduced in series inside two glass tubes. The three volatilization chambers, kept at a temperature between 20 and $22^{\circ} \mathrm{C}$, were related to the same air pump, which established a constant air stream inside the system $\left(46.2 \pm 2.3 \mathrm{~L} \mathrm{~min}^{-1}\right)$. Experiments were performed in the dark to avoid photodegradation.

At the end of four experimental durations (1, 3, 6, and $24 \mathrm{~h}$ ), leaves and PUF plugs were recovered and extracted with suitable solvents (see below). The different parts of the volatilization chamber were rinsed with ethanol and analyzed for ${ }^{14} \mathrm{C}$. The volatilization rates were calculated given the pesticide fraction adsorbed on PUF plugs and the fraction deposit on the internal walls of the volatilization chamber assuming that this fraction was related to volatilization losses. We experimentally deducted that a duration limit of $24 \mathrm{~h}$ allowed us to not have dried leaves when using cut leaves.

\section{Plant Material}

All experiments were conducted using wheat leaves sampled from plants (winter wheat, cultivar Premio, RAGT) cultivated at the Grignon experimental field site $\left(48.51^{\circ} \mathrm{N}, 1.58^{\circ} \mathrm{E}\right)$ located $30 \mathrm{~km}$ southwest of Paris (France). Leaves were detached from the plant at the realistic period of fungicide treatment in the field, corresponding to the $30-31$ and the $50-51$ growth stages. 


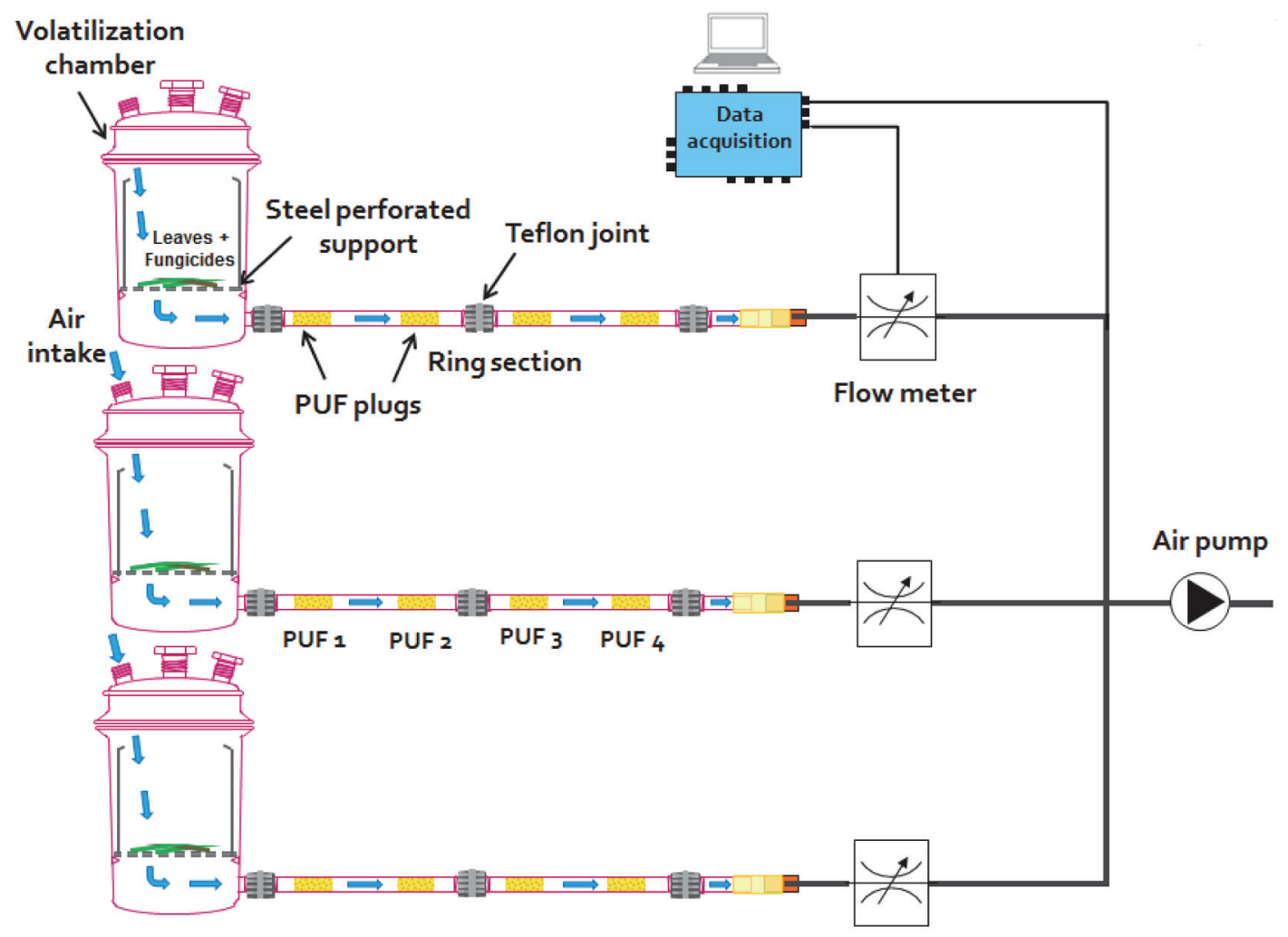

Fig. 1. Scheme of the experimental set-up in the laboratory. PUF, polyurethane foam.

\section{Pesticide Application}

Two fungicides, chlorothalonil and epoxiconazole, were used (Table 1). Commercial formulations of chlorothalonil (Banko $500\left[500 \mathrm{~g} \mathrm{~L}^{-1}\right]$; Arysta Lifescience, suspension concentrate) and epoxiconazole (Opus New [83 g L ${ }^{-1}$; BASF Agro SAS, emulsifiable concentrate) were dissolved into Milli-Q water. The concentrations of chlorothalonil and epoxiconazole in the formulated solutions were 5 and $0.83 \mathrm{~g} \mathrm{~L}^{-1}$, respectively, which corresponds to the agronomic homologated doses of 750 and $125 \mathrm{~g} \mathrm{ha}^{-1}$, respectively, in an equivalent application volume of $150 \mathrm{~L} \mathrm{ha}^{-1}$. These solutions were spiked with ${ }^{14} \mathrm{C}$-labeled fungicides to reach $19.13 \pm 0.7 \mathrm{MBq} \mathrm{L}{ }^{-1}$. [U-pheny $1{ }^{14} \mathrm{C}$ ]chlorothalonil was obtained from Syngenta (specific radioactivity, $2.11 \mathrm{MBq} \mathrm{mg}^{-1}$; radiopurity, 96.8\%), and $\left[\mathrm{U}\right.$-triazole- $\left.{ }^{14} \mathrm{C}\right]$ epoxiconazole was purchased from Izotop (specific radioactivity, $4.01 \mathrm{MBq} \mathrm{mg}^{-1}$; radiopurity, $97.9 \%$ ).

To study the effect of the formulation, a solution of pure ${ }^{14} \mathrm{C}$-epoxiconazole was prepared in a 50:50 (v/v) mixture of methanol:water by isotopic dilution with nonlabeled epoxiconazole (99.2\% purity) (Sigma-Aldrich) with a concentration of $0.04 \mathrm{~g} \mathrm{~L}^{-1}$. The mass of applied fungicide per unit surface of leaves was calculated as described by Bedos et al. (2010) (further details are provided in the Supplemental Information).

The volume of solution to be applied per unit surface of leaves was experimentally determined. To cover homogenously the whole leaf surface, 30 droplets of $2 \mu \mathrm{L}$ (final volume, $60 \mu \mathrm{L}$ per leaf) were deposited onto the adaxial surface of each wheat leaf using an electronic Eppendorf micropipette (Dominique

Table 1. Physico-chemical properties of chlorothalonil and epoxiconazole.

\begin{tabular}{|c|c|c|c|}
\hline Physico-chemical properties $\dagger$ & Unit & Chlorothalonil & Epoxiconazole \\
\hline Empirical formula & $(-)$ & $\mathrm{C}_{8} \mathrm{Cl}_{14} \mathrm{~N}_{2}$ & $\mathrm{C}_{17} \mathrm{H}_{13} \mathrm{CIFN}_{3} \mathrm{O}$ \\
\hline Structural formula & $(-)$ & $\mathrm{CN}$ & \\
\hline Molar mass & $\mathrm{g} \mathrm{mol}^{-1}$ & 265.9 & 329.8 \\
\hline Water solubility $\left(25^{\circ} \mathrm{C}, \mathrm{pH} 7\right)$ & $\mathrm{mg} \mathrm{L}^{-1}$ & 0.81 & 7.1 \\
\hline Vapor pressure & $\mathrm{Pa}$ & $7.6 \times 10^{-5}\left(25^{\circ} \mathrm{C}\right)$ & $1 \times 10^{-5}\left(20^{\circ} \mathrm{C}\right)$ \\
\hline Henry's constant & $\mathrm{Pa} \mathrm{m}^{3} \mathrm{~mol}^{-1}$ & $2.5 \times 10^{-2}\left(25^{\circ} \mathrm{C}\right)$ & $4.7 \times 10^{-4}\left(20^{\circ} \mathrm{C}\right)$ \\
\hline $\log \left(K_{\mathrm{ow}}\right)\left(25^{\circ} \mathrm{C}, \mathrm{pH} 7\right)$ & $(-)$ & 2.94 & 3.3 \\
\hline Half-life time (air) & $\mathrm{h}$ & $2.1 \times 10^{4}$ & 14.6 \\
\hline
\end{tabular}

† Data are from ANSES (2013) except for half-life time data, which are from Gouzy and Farret (2005). 
Dutscher SAS). Due to the low solubility of chlorothalonil in this solvent, only epoxiconazole was tested as a pure substance.

To get an adjuvant concentration to conform to the one used in crop treatments, the concentration of formulated fungicide solutions was higher than the pure fungicide solution. Thus, the mass of active ingredient in the formulations applied per leaf was $30 \times 10^{-5} \mathrm{~g}$ and $5 \times 10^{-5} \mathrm{~g}$ for chlorothalonil and the epoxiconazole, respectively, compared with $0.24 \times 10^{-5} \mathrm{~g}$ of epoxiconazole for the pure substance.

\section{Extraction of Polyurethane Foam Plugs}

At the end of each experiment, each PUF plug was transferred to a $120-\mathrm{mL}$ Corex tube (Dupont Instruments), extracted separately with $20 \mathrm{~mL}$ of ethanol, and shaken manually for $1 \mathrm{~min}$. The PUF plug was squeezed for 1 min using a metal spatula. This procedure was repeated five times, ensuring that ${ }^{14} \mathrm{C}$-residues trapped in the PUF plugs were totally extracted. The extraction of each PUF plug was individually analyzed to verify the functionality of the trapping system. The ${ }^{14} \mathrm{C}$-fungicides were predominantly found in the first PUF plug. For chlorothalonil, the most volatile compound used, more than $80 \%$ of the total volatilization was found on the first PUF plug (Table 2).

\section{Extraction of Leaves}

An extraction procedure following successive steps was used to describe the distribution of pesticide residues on and in plant leaves (Fig. 2). Four fractions of pesticide residues were recovered: (i) the fraction of pesticide susceptible to wash-off by rain that was assumed to correspond to the water-washable fraction, (ii) the fraction of pesticide having adsorbed on the leaf surface that was assumed to correspond to the ethanol-extracted fraction, (iii) the fraction of pesticide having penetrated into the cuticle that was assumed to correspond to the hexane-extracted fraction, and (iv) the fraction of pesticide having penetrated into the foliar tissues that was assumed to correspond to the bound residues fraction.

The choice of solvents was based on the description proposed by Leistra (2005). Three different fractions of pesticides were measured using solvents with decreasing polarity. The fraction deposit on plant leaves was extracted with a polar solvent (water). Ethanol was used as a solvent of intermediate polarity

Table 2. Extraction of formulated ${ }^{14} \mathrm{C}$-chlorothalonil, formulated ${ }^{14} \mathrm{C}$-epoxyconazole, and pure ${ }^{14} \mathrm{C}$ - epoxyconazole from polyurethane foams plugs at different experiment durations.

\begin{tabular}{|c|c|c|c|c|c|c|c|c|c|c|c|c|}
\hline \multirow{2}{*}{ Compound } & \multicolumn{4}{|c|}{ Formulated chlorothalonil } & \multicolumn{4}{|c|}{ Formulated epoxiconazole } & \multicolumn{4}{|c|}{ Pure epoxiconazole } \\
\hline & $1 \mathrm{~h}$ & $3 \mathrm{~h}$ & $6 \mathrm{~h}$ & $24 \mathrm{~h}$ & $1 \mathrm{~h}$ & $3 \mathrm{~h}$ & $6 \mathrm{~h}$ & $24 \mathrm{~h}$ & $1 \mathrm{~h}$ & $3 \mathrm{~h}$ & $6 \mathrm{~h}$ & $24 \mathrm{~h}$ \\
\hline \multicolumn{13}{|l|}{ PUF† 1, \%キ } \\
\hline Extr.§ 1 & 1.07 & 2.05 & 2.59 & 9.15 & 0.01 & 0.10 & 0.10 & 0.25 & 0.20 & 0.11 & 0.19 & 0.42 \\
\hline Extr. 2 & 0.22 & 0.53 & 0.72 & 2.52 & n.d.n & 0.02 & n.d. & 0.04 & 0.01 & 0.01 & n.d. & 0.09 \\
\hline Extr. 3 & 0.03 & 0.32 & 0.19 & 0.65 & n.d. & n.d. & n.d. & 0.01 & 0.01 & n.d. & n.d. & 0.04 \\
\hline Extr. 4 & 0.01 & 0.35 & 0.09 & 0.14 & n.d. & n.d. & n.d. & 0.01 & n.d. & n.d. & n.d. & 0.02 \\
\hline Extr. 5 & n.d. & 0.03 & 0.03 & 0.05 & n.d. & 0.01 & n.d. & n.d. & n.d. & n.d. & n.d. & 0.02 \\
\hline PUF 1_SUM, \% & 1.33 & 3.28 & 3.61 & 12.52 & 0.01 & 0.14 & 0.10 & 0.31 & 0.22 & 0.12 & 0.19 & 0.59 \\
\hline \multicolumn{13}{|l|}{ PUF $2, \%$} \\
\hline Extr. 1 & 0.15 & 0.01 & 0.03 & 0.05 & n.d. & 0.05 & 0.01 & 0.14 & 0.03 & 0.01 & 0.01 & 0.01 \\
\hline Extr. 2 & n.d. & 0.01 & 0.02 & 0.01 & n.d. & 0.01 & n.d. & 0.02 & n.d. & 0.03 & n.d. & 0.02 \\
\hline Extr. 3 & n.d. & n.d. & 0.01 & n.d. & n.d. & 0.01 & n.d. & n.d. & n.d. & n.d. & n.d. & 0.01 \\
\hline Extr. 4 & n.d. & n.d. & 0.01 & n.d. & n.d. & n.d. & n.d. & n.d. & n.d. & n.d. & n.d. & 0.01 \\
\hline Extr. 5 & n.d. & n.d. & n.d. & n.d. & n.d. & n.d. & n.d. & n.d. & n.d. & n.d. & n.d. & 0.01 \\
\hline PUF 2_SUM, \% & 0.15 & 0.02 & 0.07 & 0.06 & n.d. & 0.07 & 0.01 & 0.16 & 0.03 & 0.04 & 0.01 & 0.06 \\
\hline \multicolumn{13}{|l|}{ PUF 3, \% } \\
\hline Extr. 1 & 0.01 & n.d. & 0.01 & 0.05 & 0.01 & 0.05 & n.d. & 0.07 & 0.02 & 0.03 & 0.01 & 0.02 \\
\hline Extr. 2 & n.d. & n.d. & 0.01 & n.d. & n.d. & 0.01 & n.d. & 0.02 & n.d. & 0.01 & n.d. & 0.01 \\
\hline Extr. 3 & n.d. & n.d. & 0.01 & n.d & n.d. & n.d. & n.d. & n.d. & n.d. & n.d. & n.d. & 0.01 \\
\hline Extr. 4 & n.d. & n.d. & n.d. & n.d & n.d. & n.d. & n.d. & n.d. & n.d. & n.d. & n.d. & n.d. \\
\hline Extr. 5 & n.d. & n.d. & n.d. & n.d & n.d. & n.d. & n.d. & n.d. & n.d. & n.d. & n.d. & 0.03 \\
\hline PUF 3_SUM, \% & 0.01 & n.d. & 0.03 & 0.05 & 0.01 & 0.05 & n.d. & 0.09 & 0.02 & 0.04 & 0.01 & 0.08 \\
\hline \multicolumn{13}{|l|}{ PUF $4, \%$} \\
\hline Extr. 1 & n.d. & n.d. & 0.01 & 0.01 & n.d. & n.d. & n.d. & n.d. & 0.01 & 0.01 & 0.01 & 0.01 \\
\hline Extr. 2 & n.d. & n.d. & n.d. & 0.01 & n.d. & n.d. & n.d. & 0.02 & n.d. & n.d. & n.d. & 0.01 \\
\hline Extr. 3 & n.d. & n.d. & n.d. & n.d. & n.d. & n.d. & n.d. & n.d. & n.d. & n.d. & n.d. & 0.01 \\
\hline Extr. 4 & n.d. & n.d. & n.d. & n.d. & n.d. & n.d. & n.d. & n.d. & n.d. & n.d. & n.d. & n.d. \\
\hline Extr. 5 & n.d. & n.d. & n.d. & n.d. & n.d. & n.d. & n.d. & n.d. & n.d. & n.d. & n.d. & n.d. \\
\hline PUF 4_SUM, \% & n.d. & n.d. & 0.01 & 0.02 & n.d. & n.d. & n.d. & 0.02 & 0.01 & 0.01 & 0.01 & 0.03 \\
\hline Total SUM, \% & 1.49 & 3.29 & 3.73 & 12.64 & 0.01 & 0.27 & 0.11 & 0.57 & 0.28 & 0.21 & 0.21 & 0.76 \\
\hline
\end{tabular}

† Volatilized fraction adsorbed on polyurethane foam (PUF).

$\neq$ Total radioactivity applied $=100 \%$.

$\S$ Extraction.

१ Not detectable. 


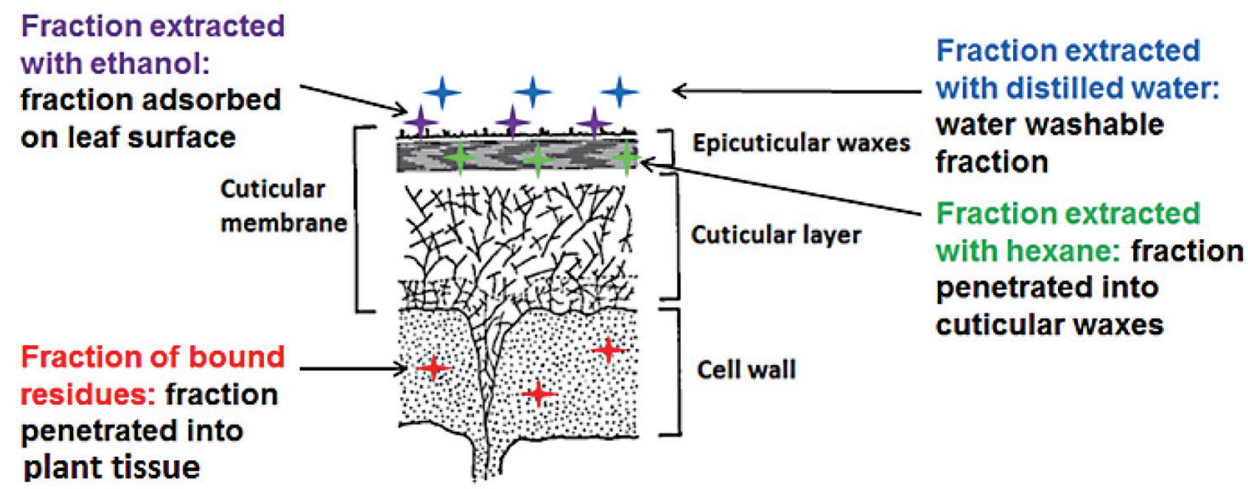

$+{ }^{14} \mathrm{C}$ labeled compounds

Fig. 2. Scheme of the distribution of pesticide residue on and in the leaf quantified at the different steps of the extraction procedure.

to quantify the pesticide fraction adsorbed on the leaf surface without affecting the leaf cuticle (McCall et al., 1986). Hexane was used to extract the pesticide penetrated into plant cuticle because it proved to have ideal properties to dissolve cuticular waxes (Rashotte et al., 2001). However, due to its very low polarity, this solvent can dissolve only limited amounts of the more polar wax constituents, so that relatively large volumes have to be applied to obtain an exhaustive extraction (Jetter et al., 2007). The duration of extraction has varied widely in previous studies, especially according to the duration of extraction of cuticular waxes. As reviewed by Jetter et al. (2007) for a large number of plant species, the standard protocol comprising two steps of 30 $s$ was used and assumed to ensure total extraction of cuticular waxes. Thus, a duration of extraction of $60 \mathrm{~s}$ was chosen for each extraction step.

At the end of each experiment, the three treated leaves introduced in each volatilization chamber were transferred to a 120-mL Corex tube and extracted simultaneously. First, $20 \mathrm{~mL}$ of Milli-Q water was added to the tube, and treated leaves were rinsed by shaking manually for $60 \mathrm{~s}$. The rinsed leaves were transferred in another test tube, soaked with $20 \mathrm{~mL}$ of ethanol, and shaken manually for $60 \mathrm{~s}$. Then the leaves were transferred to a third tube, soaked in a volume of $20 \mathrm{~mL}$ of hexane, and shaken manually for $20 \mathrm{~s}$. This step was repeated three times to apply a larger volume of solvent and to keep the same duration of extraction.

\section{Analyses}

A volume of $1 \mathrm{~mL}$ of each extract was sampled, to which $10 \mathrm{~mL}$ of scintillating cocktail (Ultima Gold XR "PERKIN") was added, and the sample was counted in a liquid scintillation counter (Tri-Carb 2100 TR, Packard). The bound residues were measured after drying the leaves for $24 \mathrm{~h}$ at $34^{\circ} \mathrm{C}$ and measuring their radioactivity content after combustion in an oxidizer (Biological Oxidizer OX 400, Zinsser) and trapping the ${ }^{14} \mathrm{CO}_{2}$ with of Oxysolve C-400 cocktail (Zinsser) before liquid scintillation counting.

\section{Results and Discussion}

\section{Overall Mass Balance Recovery}

Table 3 shows the ${ }^{14} \mathrm{C}$ balance of each experiment. We assumed that the quantified fractions correspond only to the active ingredient without taking into account the derivative metabolites because for both compounds degradation could be neglected given the short duration of the experiments (maximum 24 h) (Bedos et al., 2010; EFSA, 2008). Recovery rates within the range of 90.5 to $105.2 \%, 92.4$ to $98.5 \%$, and 99.7 to $105.2 \%$, respectively, for the formulated chlorothalonil, formulated epoxiconazole, and pure epoxiconazole were found with good reproducibility. They were calculated given the sum of the volatilized fraction and the fraction on/in leaves, including the water-washable fraction, the ethanol-extracted fraction, the hexane-extracted fraction, and bound residues. The results indicate that more than $85 \%$ of applied fungicides remained associated with the plant leaves.

\section{Pesticide Volatilization from Plant Leaves}

The chlorothalonil volatilization rate continuously evolved over time, rising from 2.8 to $14.5 \%$ of the applied radioactivity within $24 \mathrm{~h}$ after application (Fig. 3). This time evolution is in agreement with previous results found in the field for this compound (Bedos et al., 2010; van den Berg et al., 1995). In the case of epoxiconazole, the volatilization remained almost constant

Table 3. Mass balance of experiments with formulated ${ }^{14} \mathrm{C}$-chlorothalonil, formulated ${ }^{14} \mathrm{C}$-epoxyconazole, and pure ${ }^{14} \mathrm{C}$-epoxyconazole at different experiment durations.

\begin{tabular}{|c|c|c|c|c|c|c|c|c|c|c|c|c|}
\hline & \multicolumn{4}{|c|}{ Formulated chlorothalonil } & \multicolumn{4}{|c|}{ Formulated epoxiconazole } & \multicolumn{4}{|c|}{ Pure epoxiconazole } \\
\hline & $1 \mathrm{~h}$ & $3 \mathrm{~h}$ & $6 \mathrm{~h}$ & $24 \mathrm{~h}$ & $1 \mathrm{~h}$ & $3 \mathrm{~h}$ & $6 \mathrm{~h}$ & $24 \mathrm{~h}$ & $1 \mathrm{~h}$ & $3 \mathrm{~h}$ & $6 \mathrm{~h}$ & $24 \mathrm{~h}$ \\
\hline Fraction volatilized,,$\%$ & $2.8 \pm 0.5$ & $4.6 \pm 0.7$ & $5.2 \pm 0.2$ & $14.5 \pm 3.1$ & $2.3 \pm 0.3$ & $1.7 \pm 0.3$ & $1.6 \pm 0.1$ & $3.2 \pm 0.5$ & $0.3 \pm 0.0$ & $0.2 \pm 0.0$ & $0.2 \pm 0.0$ & $0.8 \pm 0.0$ \\
\hline Fraction in leaves, $\neq \%$ & $87.7 \pm 1.1$ & $99.7 \pm 2.2$ & $100.0 \pm 2.2$ & $86.7 \pm 5.9$ & $96.2 \pm 2.4$ & $94.2 \pm 11.6$ & $90.8 \pm 8.8$ & $90.7 \pm 7.6$ & $101.2 \pm 1.8$ & $99.5 \pm 2.4$ & $105.0 \pm 7.2$ & $104.2 \pm 0.8$ \\
\hline$\sum^{14} \mathrm{C}, \%$ & $90.5 \pm 1.0$ & $104.3 \pm 2.3$ & $105.2 \pm 2.3$ & $101.2 \pm 5.2$ & $98.5 \pm 2.7$ & $95.9 \pm 11.4$ & $92.4 \pm 4.4$ & $93.9 \pm 7.9$ & $101.5 \pm 1.8$ & $99.7 \pm 2.2$ & $105.2 \pm 1.8$ & $105.0 \pm 1.1$ \\
\hline
\end{tabular}

† Volatilized fraction calculated on the bases of the volatilized fraction adsorbed on polyurethane foam plugs and the fraction deposed on the internal walls of the volatilization chamber.

‡ Fraction in leaves includes the water-washable, ethanol-extracted, and hexane-extracted fractions and bound residues. 


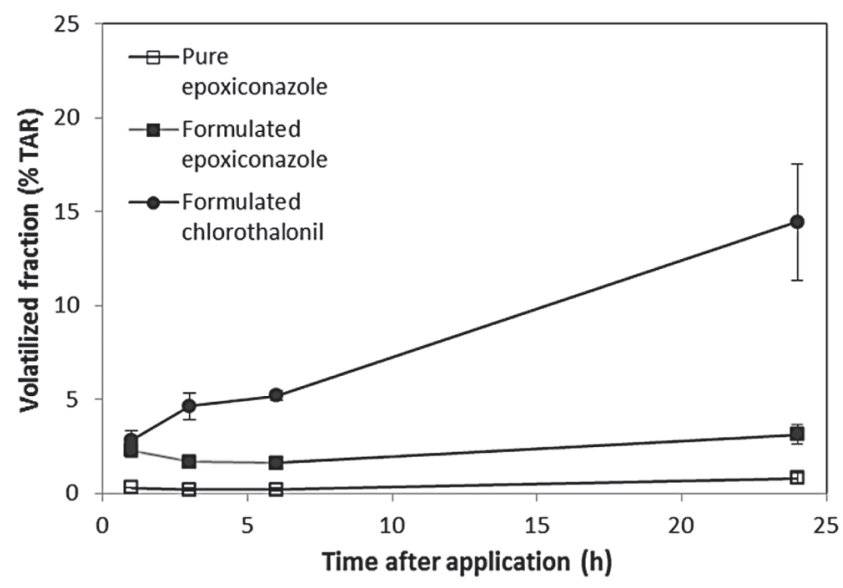

Fig. 3. Kinetics of volatilization of chlorothalonil and epoxiconazole after application on wheat leaves. TAR, total applied radioactivity $(y$ axis). The error bars represent the SDs based on three replicates.

and low within $24 \mathrm{~h}$ after the application as also found by the EFSA (2008), which concluded that the volatilization is not a significant pathway for dissipation of epoxiconazole. It was also noted that the volatilization of the formulated product showed the same behavior as observed for the pure substance, although at slightly higher rates (a maximum of 0.8 and 3.2\% measured after $24 \mathrm{~h}$ for pure and formulated epoxiconazole, respectively). The higher volatilization rate of chlorothalonil compared with epoxiconazole was expected due to the higher vapor pressure of chlorothalonil (Table 1).

\section{Pesticide Fate in Plant Leaves}

Figure 4 shows the overall balance of the distribution of fungicides between the different extracted fractions from leaves, including the water-, ethanol-, and hexane-extracted fractions and the bound residues fraction. Concerning the formulated chlorothalonil, the water-washable fraction recovered after $1 \mathrm{~h}$ was lower than the formulated epoxiconazole fraction (59 and $85 \%$, respectively). This behavior is expected due to the higher water solubility of the epoxiconazole (nine times higher than chlorothalonil water solubility). Whereas these fractions were equivalent for both formulations after $24 \mathrm{~h}$, indicating that the pesticide fraction susceptible to wash-off by rain was equivalent for both products after $24 \mathrm{~h}$. Just after fungicide application, the water-washable fraction of the formulated epoxiconazole was higher (by a factor of almost 3 ) than the water-washable fraction of the pure epoxiconazole ( 85 and $31 \%$ respectively); these fractions became equivalent $24 \mathrm{~h}$ after application (Fig. 4b, 4c). These results are in agreement with observations of Reddy and Locke (1996) on imazaquin herbicide. These authors found that, in the presence of adjuvants, rainfall washed off more than $80 \%$ of foliar residues $1 \mathrm{~h}$ after application but washed off only $60 \%$ $24 \mathrm{~h}$ after application. This was explained by the fact that, regardless of the presence or absence of adjuvants, a longer time contact with leaf surface is needed for leaf penetration of pesticides.

The ethanol extractions (Fig. 4) showed that the adsorbed fraction of the formulated chlorothalonil increased between 1 and $6 \mathrm{~h}$ after application, rising from 18 to $41 \%$. This fraction decreased to $25 \%$ of the applied amount. In contrast, for the formulated epoxiconazole, this fraction was low and remained practically constant during the $24-\mathrm{h}$ experiment $(\sim 5 \%$ of the applied epoxiconazole). A hypothesis to explain this behavior could rely on the effect of the formulation. Indeed, the adsorbed fraction of the pure epoxiconazole is higher by a factor of 6 than the adsorbed fraction of the formulated epoxiconazole. This result could suggest a faster penetration of the formulated epoxiconazole into the leaves compared with the pure epoxiconazole, thus resulting in a restricted adsorbed fraction on the leaf surface.

The penetrated fraction into cuticular waxes (Fig. 4) was almost of the same order of magnitude for both compounds with
Formulated chlorothalonil

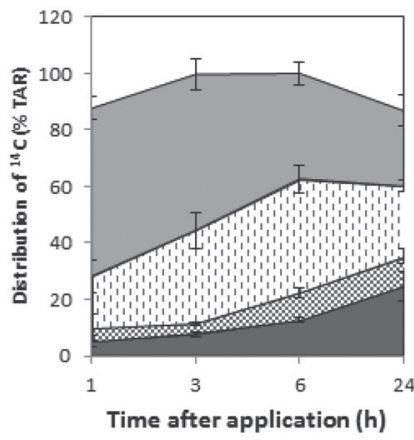

(a)
Formulated epoxiconazole

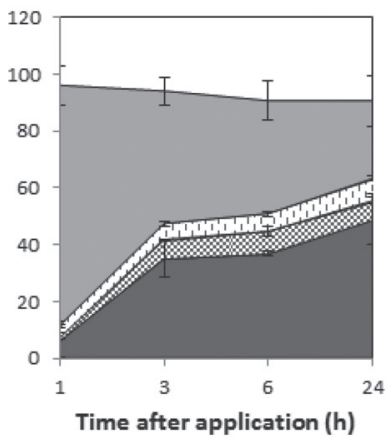

(b)
Pure epoxiconazole

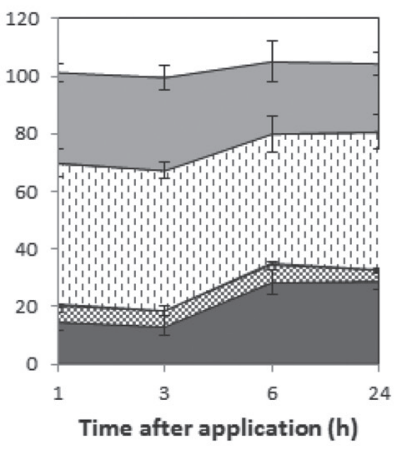

(c)

Water extractable: assumed to be the water washable fraction

$\square$ Ethanol extractable: assumed to be the adsorbed fraction on leaf surface

औexane extractable: assumed to be the penetrated fraction into cuticular waxes

Bound residues: assumed to be the penetrated fraction into plant tissue

Fig. 4. Distribution kinetics of ${ }^{14} \mathrm{C}$-labeled fungicides between the different extracted fractions from leaves, including the water-, ethanol-, and hexane-extracted fractions and the bound residues fraction. (a) Formulated chlorothalonil. (b) Formulated epoxiconazole. (c) Pure epoxiconazole. TAR, total applied radioactivity ( $y$ axis). The error bars represent the SDs based on three replicates. 
a low evolution with time. Due to the lipoidal nature of the plant cuticle-defined as a thin continuous layer $(<0.1-10 \mu \mathrm{m})$ of predominantly lipid material synthesized by the epidermal cells and deposed on their outer walls (Kirkwood, 1999)-penetration into this layer tends to increase with increasing lipophilicity of the compound and vice versa (Baker et al., 1992). Moreover, as reported by Wang and Liu (2007), this lipophilicity is described by the octanol/water partition coefficient $\left(K_{\mathrm{ow}}\right)$. In fact, the close order of magnitude of this fraction for both compounds may be linked to their close values of $K_{\text {ow }}$ (Table 1). Furthermore, no significant difference was noted between pure and formulated epoxiconazole. This proves that the rate of the fraction penetrated into the cuticular waxes is mainly cuticular dependent, being almost independent of the nature of tested products.

The penetrated fraction into foliar cells (Fig. 4) was lower for the formulated chlorothalonil than those measured for pure and formulated epoxiconazole (only $25 \%$ after $24 \mathrm{~h} \mathrm{com-}$ pared with 29 and 49\%, respectively, for pure and formulated epoxiconazole). The main effect of formulation, in the case of epoxiconazole, was the quick increase of cell penetration and bound residues formation during the first $3 \mathrm{~h}$. This bound residues fraction increased again over time, leading to higher percentages for the formulated epoxiconazole than for pure epoxiconazole ( 49.0 and $28.7 \%$, respectively, after $24 \mathrm{~h}$ ). These observations confirm the hypothesis made above on the adsorption fraction evolution of the formulated epoxiconazole. This formulation effect is in agreement with the findings of Stock and Holloway (1993), who demonstrated the action of adjuvants on the increase of pesticide penetration into the leaves. These different behaviors between chlorothalonil and epoxiconazole can be linked with the action of adjuvants, which differs depending on the mode of action of the active ingredient, as reported by de Ruiter et al. (2004). Because chlorothalonil is a contact product (Caux et al., 1996), the formulation promoted its availability on the leaf surface, resulting in a low fraction penetrated into foliar cells compared with epoxiconazole. Because epoxiconazole is a systemic product (Pareja et al., 2012), the formulation promoted its penetration into plant tissue, resulting in a high penetrated fraction into foliar cells and a low adsorbed fraction at the leaf surface (Fig. 4b) compared with chlorothalonil.

The presented results revealed that the movement of the tested pesticides occurred mainly from the leaf surface to the leaf tissue for the period of time considered here. Moreover, the pesticide fraction that penetrated into the cuticular waxes did not show significant evolution over time. The cuticle seems thus to serve only as a barrier to penetration from the surface into the plant tissue without any capacity of storage.

\section{Estimation of the Effective Fungicide Penetration Rate Constant into Foliar Tissue}

The pesticide penetration into leaf cuticle is a reversible process explainable by the diffusion mechanism (Schreiber and Schönherr, 1993). In fact, the reverse movement is possible and can occur when the pesticide concentration on the leaf surface is lower than the concentration inside the plant (Leistra, 2005). The pesticide penetration into plant tissue is considered to be an irreversible process (Leistra, 2005). The kinetics of pesticide penetration into plant tissue were described by McCall (1989) as a first-order process as follows:

$M(t)=M_{0} \times\left(1-e^{-k_{\mathrm{pen}} t}\right)$

where $M(t)$ is the percentage of pesticide penetrated into plant tissue at time $t, M_{0}$ is the total percentage of pesticide applied on the leaf surface $(=100 \%), k_{\text {pen }}$ is the penetration rate constant $\left(\mathrm{d}^{-1}\right)$, and $t$ is time $(\mathrm{d})$.

The rate constants of the tested compounds were calculated given the slopes of the regression curves plotting $\operatorname{Ln}\left(1-M_{\mathrm{t}} / M_{0}\right)$ against $t$ (Fig. 5). Pure epoxiconazole presents a $k_{\text {pen }}$ of $0.17 \pm$ $0.07 \mathrm{~d}^{-1}\left(R^{2}=0.52\right)$, which corresponds to a penetration half-life $\left(\mathrm{PT}_{1 / 2}\right)$ of $4 \mathrm{~d}$. Formulated epoxiconazole presents a $k_{\mathrm{pen}}$ of 0.47 $\pm 0.20 \mathrm{~d}^{-1}\left(\mathrm{PT}_{1 / 2}=1.5 \mathrm{~d} ; R^{2}=0.66\right)$. As argued above, the fact that the penetration rate constant of formulated epoxiconazole is almost three times that of pure epoxiconazole is related to the effect of the formulation. Formulated chlorothalonil presents a $k_{\text {pen }}$ of $0.23 \pm 0.09 \mathrm{~d}^{-1}\left(\mathrm{PT}_{1 / 2}=3 \mathrm{~d} ; R^{2}=0.97\right)$. Leistra and van den Berg (2007) estimated a lower penetration rate constant

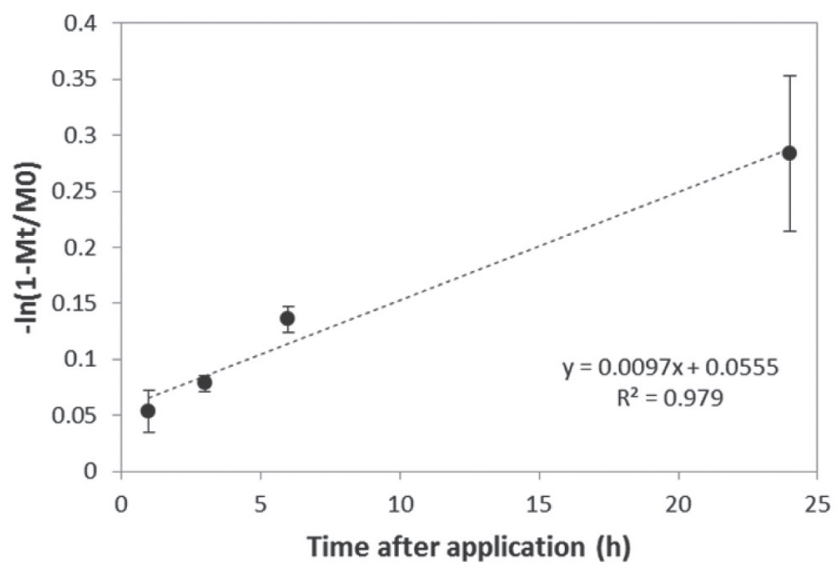

(a)

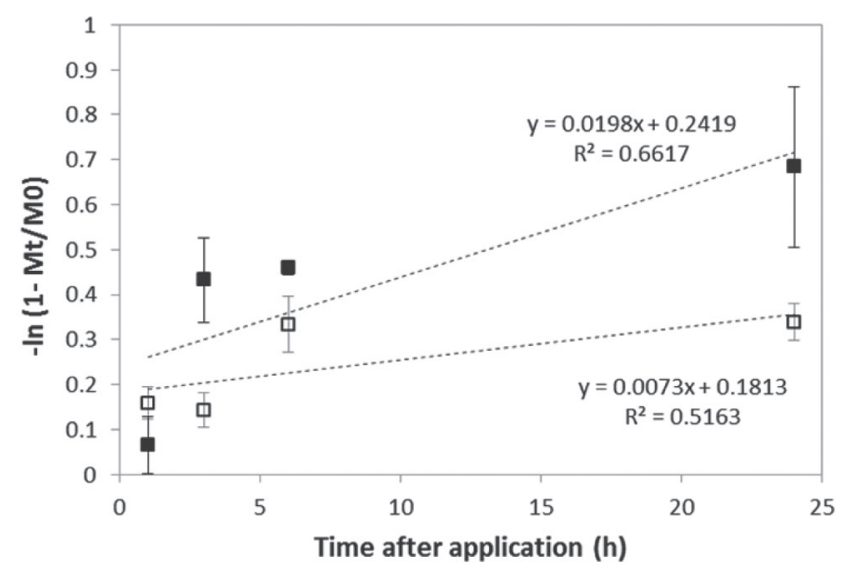

(b)

Fig. 5. Penetration into plant tissue of chlorothalonil and epoxiconazole applied on wheat leaves as a function of time. Closed circle, formulated chlorothalonil; open square, pure epoxiconazole; closed square, formulated epoxiconazole. The dashed lines represent the first-order kinetics. The error bars represent the SDs based on three replicates. 
for chlorothalonil applied on potato leaves. Leaf penetration of formulated chlorothalonil was lower $\left(k_{\text {pen }}=0.14 \mathrm{~d}^{-1} ; \mathrm{PT}_{1 / 2}\right.$ $=5 \mathrm{~d}$ ). This difference may be explained by the differentiated morphological characteristics of leaf surface for potatoes and wheat. In fact, potato leaves are densely covered with glandular hairs (Cutter, 1992), whereas leaf hairs are absent in most wheat genotypes (Mansing, 2010). This morphological characteristic governs the wettability of the leaf surface, which affects pesticide penetration into the leaves (Xu et al., 2011). In fact, in the case of potatoes leaf penetration could have a minor role because a fraction of sprayed droplets could bead up and roll off and not adhere to cuticular waxes and the leaf tissue. Furthermore, according to the classification proposed by Leistra (2005) for formulated pesticides, the penetration of epoxiconazole occurs at a moderate rate, whereas the penetration of chlorothalonil occurs at a slow rate, which is in accordance with their mode of action.

\section{Conclusions}

The experiment described here allows direct simultaneous measurements of volatilization and penetration of pesticides applied on the leaf surface under controlled conditions. The high recovery rates within the range of 90.5 to $105.2 \%$ of the applied radioactivity and the good reproducibility demonstrate the functional performance of the system, in particular verifying the functionality of the trapping system of gaseous emission, which allowed the quantification of low rates of volatilization. In parallel to volatilization, the adopted working assumption for the leaf extraction procedure allowed a refined description of the leaf penetration process by distinguishing the pesticide fractions residing at the different foliar compartments. Using data from the leaf tissue compartment, a first-order kinetic was estimated. Penetration rate constants were found to be in agreement with the few existing data in the literature and with the range proposed by Leistra (2005). Volatilization and pesticide distribution on or in plant leaf for both compounds were found to be in agreement with their physicochemical properties. Nevertheless, the effect of formulation was significant, especially for epoxiconazole.

These experimental results provide (i) required parameters for mechanistic models describing volatilization of fungicides applied on plants, which are scarce in the literature, and (ii) the basis for further development of a mechanistic description of the pesticide leaf penetration by identifying relationships between penetration rate constant and their physicochemical properties.

However, using cut leaves may have an effect on the leaf penetration process of pesticides because the leaves are no longer linked to the vascular system of the plant. Considering this potential effect, we limited the duration of our experiments to 24 $\mathrm{h}$ to avoid dried leaves. The pesticide photodegradation process was not investigated in this study, which is another restriction of the system. This is due to the fact that the experimental durations chosen to study the volatilization and the leaf penetration are too short for photodegradation.

\section{Acknowledgments}

This study is part of the ECHAP project, which is supported by the research program "Assessing and reducing environmental risks from plant protection products" funded by the French Ministries in charge of
Ecology and Agriculture (coordination C. Robert) The authors thank Syngenta for supplying ${ }^{14} \mathrm{C}$-labeled chlorothalonil.

\section{References}

ANSES. 2013. AGRITOX-Base de données sur les substances actives phytopharmaceutiques. www.agritox.anses.fr/php/fiches.php (accessed 6 Oct. 2015).

Bakker, D.J., A.J. Gilbert, D. Gottschild, T. Kuchnicki, R.W.P.M. Laane, J.B.H.J. Linders, D. Van De Meent, M.H.M.M. Montforts, J. Pino, J.W. Pol, and N.M. Van Straalen. 1999. Implementing atmospheric fate in regulatory risk assessment of pesticides: (How) can it be done? Water Air Soil Pollut. 115:257-266. doi:10.1023/A:1005290414601

Baker, E.A., A.L. Hayes, and R.C. Butler. 1992. Physicochemical properties of agrochemicals: Their effects on foliar penetration. Pestic. Sci. 34:167-182. doi:10.1002/ps.2780340212

Bedos, C., M.F. Rousseau-Djabri, B. Loubet, B. Durand, D. Flura, O. Briand, and E. Barriuso. 2010. Fungicide volatilization measurements: Inverse modeling, role of vapor pressure, and state of foliar residue. Environ. Sci. Technol. 44:2522-2528. doi:10.1021/es9030547

Bedos, C., P. Cellier, R. Calvet, E. Barriuso, and B. Gabrielle. 2002. Mass transfer of pesticides into the atmosphere by volatilization from soils and plants: Overview. Agronomie 22:21-33. doi:10.1051/agro:2001003

Boehncke, A., J. Siebers, and H.G. Nolting. 1990. Investigations of the evaporation of selected pesticides from natural and model surfaces in field and laboratory. Chemosphere 21:1109-1124. doi:10.1016/0045-6535(90)90132-D

Breeze, V.G., J.C. Simmons, and M.O. Roberts. 1992. Evaporation and uptake of the herbicide 2,4-D-butyl applied to barley leaves. Pestic. Sci. 36:101-107. doi:10.1002/ps.2780360204

Caux, P.Y., R. Kent, G. Fan, and G. Stephenson. 1996. Environmental fate and effects of chlorothalonil: A Canadian perspective. Crit. Rev. Environ. Sci. Technol. 26:45-93. doi:10.1080/10643389609388486

Chamel, A. 1986. Absorption of herbicides: Study of the cuticular penetration using isolated cuticule. Physiol. Veg. 24:491-508.

Cutter, E. 1992. Structure and development of the potato plant. In: P. Harris, editor, The potato crop. World Crop Series. Springer, Dordrecht, the Netherlands. p. 65-161.

de Ruiter, H., H.J. Holterman, C. Kempenaar, and J.C. Zande. 2003. Influence of adjuvants and formulations on the emission of pesticides to the atmosphere: A literature study for the Dutch Research Programme Pesticides and the Environment (DWK) theme C-2, Plant Research International, Wageningen, the Netherlands.

de Ruiter, H., C. Kempenaar, and M. Blom-Zandstra. 2004. Foliar absorption of crop protection agents: Influence of cpa properties, formulation and plant species: A literature study for the Dutch research programme pesticides and the environment (DWK-359) theme B-2, Plant Research International, Wageningen, the Netherlands.

EFSA. 2008. Conclusion regarding the peer review of the pesticide risk assessment of the active substance: Epoxiconazole. EFSA, Parma, Italy.

Führ, F., P. Burauel, M. Dust, W. Mittelstaedt, T. Pütz, G. Reinken, and A. Stork. 1998. Comprehensive tracer studies on the environmental behavior of pesticides: The lysimeter concept. American Chemical Society Symposium Series 699:1-20. doi:10.1021/bk-1998-0699.ch001

Gauvrit, C., and J. Dufour. 1990. Effects of adjuvants on herbicidal action: I. Effects of a mixture of adjuvants on diclofop-methyl retention and penetration in wheat and ryegrass. Agronomie 10:759-765. doi:10.1051/ agro: 19900907

Gouzy, A. and Farret, R. 2005. Détermination des pesticides à surveiller dans le compartiment aérien: Approche par Hiérarchisation. Report no. NINERIS-DRC-MECO-CGR-143/2005-Ago. Ineris, Verneuil-enHalatte, France.

Jetter, R., L. Kunst, and A.L. Samuels. 2007. Composition of plant cuticular waxes. In: M. Riederer, C. Muller, editors, Annual plant reviews. Volume 23. Biology of the plant cuticle. Blackwell, Hoboken, NJ. p. 145-181.

Kerler, F., and J. Schönherr. 1988. Accumulation of lipophilic chemicals in plant cuticles: Prediction from octanol/water partition coefficients. Arch. Environ. Contam. Toxicol. 17:1-6. doi:10.1007/BF01055146

Kirkwood, R.C. 1999. Recent developments in our understanding of the plant cuticle as a barrier to the foliar uptake of pesticides. Pestic. Sci. 55:69-77. doi:10.1002/(SICI)1096-9063(199901)55:1<69::AID-PS860>3.0.CO;2-H

Kirsch, T., F. Kaffarnik, M. Riederer, and L. Schreiber. 1997. Cuticular permeability of the three tree species Prunus iaurocerasus L., Ginkgo biloba L. and Juglans regia L.: Comparative investigation of the transport properties of intact leaves, isolated cuticles and reconstituted cuticular waxes. J. Exp. Bot. 48:1035-1045. doi:10.1093/jxb/48.5.1035 
Kromer, T., H. Ophoff, A. Stork, and F. Führ. 2004. Photodegradation and volatility of pesticides. Environ. Sci. Pollut. Res. 11:107-120. doi:10.1007/ BF02979710

Kubiak, R. 2002. Experiments in a volatilization chamber under simulated outdoor conditions: A contribution to a better understanding of field dissipation studies, terrestrial field dissipation studies. ACS Symposium Series. American Chemical Society 842:257-272.

Leistra, M., and A. Wolters. 2004. Computations on the volatilisation of the fungicide fenpropimorph from plants in a wind tunnel. Water Air Soil Pollut. 157:133-148. doi:10.1023/B:WATE.0000038883.86688.83

Leistra, M. 2005. Estimating input data for computations on the volatilisation of pesticides from plant canopies and competing processes. Alterra-rapport 1256. Alterra, Wageningen, the Netherlands.

Leistra, M., J.H. Smelt, J.H. Weststrate, F. van den Berg, and R. Aalderink. 2006 Volatilization of the pesticides chlorpyrifos and fenpropimorph from a potato crop. Environ. Sci. Technol. 40:96-102. doi:10.1021/es051248x

Leistra, M., and F. van den Berg. 2007. Volatilization of parathion and chlorothalonil from a potato crop simulated by the PEARL model. Environ. Sci. Technol. 41:2243-2248. doi:10.1021/es0627242

Lichiheb, N., E. Personne, C. Bedos, and E. Barriuso. 2014. Adaptation of a resistive model to pesticide volatilization from plants at the field scale: Comparison with a dataset. Atmos. Environ. 83:260-268. doi:10.1016/j. atmosenv.2013.11.004

Mansing, J.S. 2010. Characterization of wheat (Triticum spp.) genotypes through morphological, chemical and molecular markers. University of Agricultural Science, Dharwad, India.

McCall, P.J., L.E. Stafford, P.S. Zorner, and P.D. Gavit. 1986. Modeling the foliar behavior of atrazine with and without crop oil concentrate on giant foxtail and the effect of tridiphane on the model rate constants. J. Agric. Food Chem. 34:235-238. doi:10.1021/jf00068a020

McCall, P.J. 1989. Quantitative modelling of the effects of physical and chemical parameters on the foliar penetration of pesticides and its potential for predicting field behaviour. Aspects Appl. Biol./Assoc. Appl. Biol. 21:185-201.

Pareja, L., M. Colazzo, A. Pérez-Parada, N. Besil, H. Heinzen, B. Böcking, V. Cesio, and A.R. Fernández-Alba. 2012. Occurrence and distribution study of residues from pesticides applied under controlled conditions in the field during rice processing. J. Agric. Food Chem. 60:4440-4448. doi:10.1021/ jf205293j

Rashotte, A.M., M.A. Jenks, and K.A. Feldmann. 2001. Cuticular waxes on eceriferum mutants of Arabidopsis thaliana. Phytochemistry 57:115-123. doi:10.1016/S0031-9422(00)00513-6

Reddy, K.N., and M.A. Locke. 1996. Imazaquin spray retention, foliar washoff and runofflosses under simulated rainfall. Pestic. Sci.48:179-187. doi:10.1002/ (SICI) 1096-9063(199610)48:2<179::AID-PS457>3.0.CO;2-M

Rüdel, H. 1997. Volatilisation of pesticides from soil and plant surfaces. Chemosphere 35:143-152. doi:10.1016/S0045-6535(97)00146-X

Santier, S., and A. Chamel. 1998. Reassessment of the role of cuticular waxes in the transfer of organic molecules through plant cuticles. Plant Physiol. Biochem. 36:225-231. doi:10.1016/S0981-9428(97)86879-9
Satchivi, N.M., E.W. Stoller, L.M. Wax, and D.P. Briskin. 2001. A nonlinear dynamic simulation model for xenobiotic transport and whole plant allocation following foliar application: III. Influence of chemical properties, plant characteristics, and environmental parameters on xenobiotic absorption and translocation. Pestic. Biochem. Physiol. 71:77-87. doi:10.1006/ pest.2001.2558

Schönherr, J., and P. Baur. 1994. Modelling penetration of plant cuticles by crop protection agents and effects of adjuvants on their rates of penetration. Pestic. Sci. 42:185-208. doi:10.1002/ps.2780420308

Schreiber, L., and J. Schönherr. 1993. Mobilities of organic compounds in reconstituted cuticular wax of barley leaves: Determination of diffusion coefficients. Pestic. Sci. 38:353-361. doi:10.1002/ps.2780380413

Stock, D., and P.J. Holloway. 1993. Possible mechanisms for surfactant-induced foliar uptake of agrochemicals. Pestic. Sci. 38:165-177. doi:10.1002/ ps.2780380211

Stork, A., R. Witte, and F. Führ. 1994. A wind tunnel for measuring the gaseous losses of environmental chemicals from the soil/plant system under field-like conditions. Environ. Sci. Pollut. Res. 1:234-245. doi:10.1007/ BF02986536

Trapp, S., C. McFarlane, and M. Matthies. 1994. Model for uptake of xenobiotics into plants: Validation with bromacil experiments. Environ. Toxicol. Chem. 13:413-422. doi:10.1002/etc.5620130308

Trapp, S., and M. Matthies. 1995. Generic one-compartment model for uptake of organic chemicals by foliar vegetation. Environ. Sci. Technol. 29:23332338. doi:10.1021/es00009a027

van den Berg, F., G. Bor, and R.A. Smidt. 1995. Volatilization of parathion and chlorothalonil after spraying onto a potato crop. Report/DLO-Winand Staring Centre 102. DLO Winand Staring Centre, Wageningen, the Netherlands.

van den Berg, F., R. Kubiak, W.G. Benjey, M.S. Majewski, S.R. Yates, G.L. Reeves, J.H. Smelt, and A.M.A. Van der Linden. 1999. Emission of the pesticides into the air. Water Air Soil Pollut. 115:195-218. doi:10.1023/A:1005234329622

Viel, J.F., and S.T. Richardson. 1993. Lymphoma, multiple myeloma and leukaemia among French farmers in relation to pesticide exposure. Soc. Sci. Med. 37:771-777. doi:10.1016/0277-9536(93)90371-A

Wang, C.J., and Z.Q. Liu. 2007. Foliar uptake of pesticides: Present status and future challenge. Pestic. Biochem. Physiol. 87:1-8. doi:10.1016/j. pestbp.2006.04.004

Willis, G., and L. McDowell. 1987. Pesticide persistence on foliage. In: G. Ware, editor, Reviews of environmental contamination and toxicology. Springer, New York. p. 23-73.

Wolters, A. 2003. Pesticide volatilization from soil and plant surfaces: Measurements at different scales versus model predictions. Institute of Chemistry and Dynamics of the Geosphere, Julich, Germany.

Xu, L., H. Zhu, H.E. Ozkan, W.E. Bagley, and C.R. Krause. 2011. Droplet evaporation and spread on waxy and hairy leaves associated with type and concentration of adjuvants. Pest Manag. Sci. 67:842-851. doi:10.1002/ ps. 2122 